\title{
Cardiovascular Diseases And Psychiatric Disorders During The Diagnostic Workup Of Suspected Hematological Malignancy
}

This article was published in the following Dove Press journal: Clinical Epidemiology

\author{
Qianwei Liu' \\ Therese ML Andersson ${ }^{2}$ \\ Anna Jöud (1D) 3,4 \\ Qing Shen ${ }^{2}$ \\ Maria EC Schelin (1D) 3,5 \\ Patrik KE Magnusson (iD ${ }^{2}$ \\ Karin E Smedby ${ }^{6}$ \\ Fang Fang'
}

'Institute of Environmental Medicine, Karolinska Institutet, Stockholm, Sweden; ${ }^{2}$ Department of Medical Epidemiology and Biostatistics, Karolinska Institutet, Stockholm, Sweden; ${ }^{3}$ Lund University, Department of Clinical Sciences Lund, Orthopaedics, Lund, Sweden; ${ }^{4}$ Lund University, Department of Laboratory Medicine, Occupational and

Environmental Medicine, Lund, Sweden; ${ }^{5}$ Institute for Palliative Care, IKVL, Lund University and Region Skåne, Lund, Sweden; ${ }^{6}$ Clinical Epidemiology Division, Department of Medicine, Karolinska Institutet, Stockholm, Sweden
Correspondence: Fang Fang Institute of Environmental Medicine, Karolinska Institutet, Box 23109, 10435 Stockholm, Sweden

Tel +46852486I3I

Email fang.fang@ki.se
Background: Little attention has been given to the risk of cardiovascular and psychiatric comorbidities during the clinical evaluation of a suspected hematological malignancy.

Methods: Based on Skåne Healthcare Register, we performed a population-based cohort study of 1,527,449 individuals residing during 2005-2014 in Skåne, Sweden. We calculated the incidence rate ratios (IRRs) of cardiovascular diseases or psychiatric disorders during the diagnostic workup of 5495 patients with hematological malignancy and 18,906 individuals that underwent a bone marrow aspiration or biopsy or lymph node biopsy without receiving a diagnosis of any malignancy ("biopsied individuals"), compared to individuals without such experience (i.e., reference).

Results: There was a higher rate of cardiovascular diseases during the diagnostic workup of patients with hematological malignancy (overall IRR, 3.3; 95\% CI, 2.9 to 3.8; greatest IRR for embolism and thrombosis, 8.1; 95\% CI, 5.2 to 12.8) and biopsied individuals (overall IRR, 4.9; 95\% CI, 4.6 to 5.3; greatest IRR for stroke, 37.5; 95\% CI, 34.1 to 41.2), compared to reference. Similarly, there was a higher rate of psychiatric disorders during the diagnostic workup of patients with hematological malignancy (IRR, 2.1;95\% CI, 1.5 to 2.8) and biopsied individuals (IRR, 3.1; 95\% CI, 2.9 to 3.4). The rate increases were greater around the time of diagnosis or biopsy, compared to thereafter, for both outcomes.

Conclusion: There were higher rates of cardiovascular diseases and psychiatric disorders during the diagnostic workup of a suspected hematological malignancy, regardless of the final diagnosis.

Keywords: hematological malignancy, cardiovascular diseases, psychiatric disorders, diagnostic workup

\section{Introduction}

Patients with hematological malignancy have been shown to be at elevated risks of cardiovascular diseases $^{1,2}$ and psychiatric disorders ${ }^{3,4}$ during follow-up. Cardiovascular and psychiatric comorbidities have further been related to inferior patient outcome and lower likelihood of receiving treatment with curative intent. ${ }^{5-8}$ Surveillance and intervention of cardiovascular and psychiatric comorbidities at an early stage could therefore make more patients eligible for curative treatment and improve prognosis. Previous studies have predominantly focused on cardiovascular diseases and psychiatric disorders during the primary treatment of hematological malignancy ${ }^{9,10}$ or as a long-term health risk among survivors of hematological malignancy. ${ }^{11-13}$ Little attention has been given to the period of the clinical 
evaluation of a suspected malignancy. To this end, we assessed the risks of cardiovascular diseases and psychiatric disorders during the diagnostic workup of patients with hematological malignancy, and among individuals that underwent a similar evaluation but did not receive a cancer diagnosis and individuals that never underwent a diagnostic workup for suspected hematological malignancy. We also contrasted such risks during the diagnostic workup to that of the time after the diagnostic workup.

\section{Methods}

\section{Study Design}

Based on the Total Population Register, we identified a cohort of 1,527,449 individuals residing during 2005-2014 in Skåne, Sweden. ${ }^{14}$ Through the individually unique personal identity numbers assigned to all Swedish residents, we cross-linked the cohort to the Cancer Register and Causes of Death Register and individually followed the cohort participants from January 1, 2005, date of migration to Skåne, or date of birth, whichever came later, until a diagnosis of any cancer (whether or not hematological malignancy), migration out of Skåne, death, or December 31 2014, whichever occurred first. After excluding 54,245 with a prevalent cancer at cohort entry, we included $1,473,204$ participants in the final cohort (Supplementary Figure S1).

\section{Comparison Groups}

Reporting of newly diagnosed cancer by clinicians and pathologists has been required by Swedish law since 1958, and the completeness of the Swedish Cancer Register approaches $100 \%$. Through the Cancer Register, we identified 5495 participants of the study cohort that received a new diagnosis of hematological malignancy during the follow-up (Table 1). This group was defined as exposed to the diagnostic workup of a suspected hematological malignancy, i.e., primary exposure group. The Swedish 10th revision of the International Classification of Diseases (ICD-10) codes used to identify hematological malignancies are listed in Supplementary Table S1.

Individuals that undergo an aspiration or biopsy of bone marrow or lymph node biopsy without eventually receiving a diagnosis of malignancy experience similar diagnostic procedures as patients with hematological malignancy. We therefore defined individuals that underwent an aspiration or biopsy of bone marrow or lymph node biopsy but without receiving a diagnosis of any
Table I Characteristics Of Patients With Hematological Malignancy And Individuals That Underwent A Bone Marrow Or Lymph Node Biopsy, A Population-Based Cohort Study During 2005-2014 In Skåne, Sweden

\begin{tabular}{|c|c|c|}
\hline Characteristics & $\begin{array}{l}\text { Patients With } \\
\text { Hematological } \\
\text { Malignancy }^{\mathrm{a}}\end{array}$ & $\begin{array}{l}\text { Biopsied } \\
\text { Individuals }^{\mathbf{b}}\end{array}$ \\
\hline $\begin{array}{l}\text { No. of patients or } \\
\text { individuals }\end{array}$ & 5495 & 18,906 \\
\hline Male (\%) & 3007 (54.7\%) & $8673(45.9 \%)$ \\
\hline $\begin{array}{l}\text { Median age at diagnosis or } \\
\text { biopsy, years }\end{array}$ & 70 & 56 \\
\hline $\begin{array}{l}\text { Civil status } \\
\text { - Cohabitating } \\
\text { - Non-cohabitating }\end{array}$ & $\begin{array}{l}2917(53.1 \%) \\
2578(46.9 \%)\end{array}$ & $\begin{array}{l}8394(44.4 \%) \\
10,512(55.6 \%)\end{array}$ \\
\hline $\begin{array}{l}\text { Preexisting cardiovascular } \\
\text { diseases at diagnosis or } \\
\text { biopsy } \\
\text { - Yes } \\
\text { - No }\end{array}$ & $\begin{array}{l}2749(50.0 \%) \\
2746(50.0 \%)\end{array}$ & $\begin{array}{l}7062(37.4 \%) \\
I I, 844(62.6 \%)\end{array}$ \\
\hline $\begin{array}{l}\text { Preexisting psychiatric } \\
\text { disorders at diagnosis or } \\
\text { biopsy } \\
\text { - Yes } \\
\text { - No }\end{array}$ & $\begin{array}{l}961(17.5 \%) \\
4534(82.5 \%)\end{array}$ & $\begin{array}{l}5570(29.5 \%) \\
13,336(70.5 \%)\end{array}$ \\
\hline
\end{tabular}

Notes: ${ }^{\text {IIncluding }} 784$ patients with leukemia (excluding chronic lymphoid leukemia), 322 patients with myelodysplastic syndrome, 474 patients with myeloproliferative neoplasm, 767 patients with myeloma and 3148 patients with lymphoma (including chronic lymphoid leukemia). 'Including 2050 individuals with bone marrow aspiration or biopsy and 16,856 patients with lymph node biopsy.

cancer during the 6 weeks thereafter as the secondary exposure group. This group was referred to as "biopsied individuals". The Skåne Healthcare Register (SHR) contains information on healthcare provided at all levels in this region, including patient characteristics (age, sex, and birthdate), healthcare provider (specialist or primary care), date of healthcare visit, diagnoses, and surgical or nonsurgical procedure codes. We identified biopsied individuals through SHR using corresponding procedure codes.

The primary and the secondary exposure groups started to accumulate exposed person-time from the start until the end of the diagnostic workup. Participants of the cohort that were not identified as patients with hematological malignancy or biopsied individuals during follow-up contributed all person-time to the reference group from cohort entry. Because we allowed each participant to have multiple events of cardiovascular diseases and psychiatric disorders, in the reference group, we also included person-time 
accumulated before the defined diagnostic workup of patients with hematological malignancy as well as the biopsied individuals. As a result, an outcome of interest could also occur during the unexposed person-time of the exposure groups.

\section{Definition Of Diagnostic Workup}

We defined a diagnostic workup of cancer as the time period starting from the first suspicion of cancer until the start of treatment. According to the Swedish national cancer care program, the median waiting time from the first specialist visit to diagnosis is 3 weeks for lymphoma, ${ }^{15}$ 2 weeks for myeloma, ${ }^{16}$ and 1 week for acute leukemia. ${ }^{17}$ Because the first suspicion of cancer might arise before the first specialist visit, for each patient of hematological malignancy, we calculated the weekly numbers of healthcare visits during the 12 weeks before and the 12 weeks after the diagnosis of hematological malignancy. We used logistic regression to identify the week from which the weekly number of healthcare visits increased statistically significantly compared to the week before. We found that patients with lymphoma had a statistically significantly increased number of healthcare visits during the 5th week before diagnosis, compared to before (Supplementary Figure S2). For patients with myeloma it was the 3rd week, and for patients with leukemia, myelodysplastic syndrome, and myeloproliferative neoplasm it was the 1st week, before diagnosis. We accordingly defined the start of diagnostic workup as the start of the week where the number of healthcare visits increased statistically significantly compared to before. The waiting time between diagnosis and start of primary treatment is in general 1 week for acute leukemia and aggressive lymphoma in Sweden. ${ }^{18,19} \mathrm{We}$ defined therefore the diagnostic workup as the time interval starting from 1 week before diagnosis until 1 week after diagnosis for patients with leukemia, myelodysplastic syndrome, and myeloproliferative neoplasm, from 3 weeks before until 1 week after diagnosis for patients with myeloma, and from 5 weeks before until 1 week after diagnosis for patients with lymphoma. To contrast the rates of cardiovascular diseases and psychiatric disorders during the diagnostic workup with such rates after initiation of primary treatment, we defined the 6 months after the defined diagnostic workup as the post-diagnostic period for respective patients.

Individuals undergoing bone marrow aspiration or biopsy were considered as having similar diagnostic procedures as patients with leukemia, whereas individuals undergoing lymph node biopsy are likely to have similar diagnostic procedures as patients with lymphoma. ${ }^{20,21} \mathrm{We}$ defined accordingly the diagnostic workup as the time interval from 1 week before biopsy until 1 week after biopsy for individuals receiving bone marrow aspiration or biopsy, and from 5 weeks before until 1 week after biopsy for individuals receiving lymph node biopsy. We included only the first diagnostic workup for each biopsied individual, if more than one diagnostic workup was identified. Post-diagnostic period was defined as the 6-month period after the defined diagnostic workup for these individuals, similar to patients with hematological malignancy. If a cancer diagnosis or a new diagnostic workup of suspected hematological malignancy occurred during the post-diagnostic period of biopsied individuals, the postdiagnostic period ended at the day of such event $(1.1 \%$ of all biopsied individuals).

\section{Outcome Measures}

Outcomes of interest included specialist healthcare visits with a primary diagnosis of cardiovascular diseases or psychiatric disorders. We used ICD-10 codes I00-I99 to identify cardiovascular diseases and F10-F99 to identify psychiatric disorders (Supplementary Table S2). Among cardiovascular diseases, we specifically studied myocardial infarction, embolism or thrombosis, heart failure, stroke, and hypertension. Among psychiatric disorders, we specifically studied stress reaction or adjustment disorder, depression, and anxiety. Repeated diagnoses were taken into account apart from consecutive diagnoses that occurred within 28 days of each other, which were considered as one event.

\section{Statistical Analyses}

We calculated the unadjusted incidence rates (IRs) of cardiovascular diseases and psychiatric disorders during the diagnostic workup and post-diagnostic period of the two exposure groups as well as among the reference, using number of diagnoses divided by accumulated personmonths at risk. We calculated the incidence rate ratios (IRRs) and 95\% confidence intervals (CIs) by comparing the IRs of the exposure groups with that of the reference using Poisson regression. In all statistical models, we adjusted for attained age and calendar year, sex, civil status, and preexisting cardiovascular disease or psychiatric disorder. Because of the repeated outcome measures, we also used clustered sandwich estimator to account for correlated data in all models. To reduce concerns of 
residual confounding, we used conditional Poisson regression to perform a within-individual analysis where the IRs of cardiovascular diseases and psychiatric disorders during the diagnostic workup and post-diagnostic period were compared with the IRs of the same individual before the diagnostic workup, among patients with hematological malignancy and biopsied individuals.

We also performed several analyses focusing on the diagnostic workup alone. First, to assess potential effect modifiers of the studied associations, we performed subgroup analyses by age at diagnosis or biopsy, sex, calendar period, civil status, and preexisting cardiovascular disease or psychiatric disorder. Patients with hematological malignancy and biopsied individuals might have a greater access to healthcare providers during their diagnostic workup, resulting a higher risk of being diagnosed with cardiovascular diseases or psychiatric disorders. To alleviate concern of such surveillance bias, in an additional sensitivity analysis, we further adjusted for frequency of healthcare visits in the statistical model. Frequency of healthcare visits was calculated as number of hospital visits divided by number of days accumulated during the diagnostic workup and the reference period. To provide a direct comparison between patients with hematological malignancy and the biopsied individuals, we also compared the rates of cardiovascular diseases and psychiatric disorders during the diagnostic workup between patients with hematological malignancy and biopsied individuals. Finally, as patients with newly diagnosed leukemia and lymphoma are usually planned to be treated with anthracyclines and targeted drugs that may impact cardiac function, these patients are frequently referred to cardiologists for pre-therapeutic evaluation or intervention, where new cardiovascular diagnoses may be made. To reduce concern of such bias, we further compared IRs of cardiovascular diseases and psychiatric disorders before and after diagnosis or biopsy, during the diagnostic workup.

All analyses were performed in SAS 9.4 (SAS Institute) and Stata 15.1 (StataCorp LP). The Ethical Review Board in Stockholm, Sweden approved the study.

\section{Results}

\section{Baseline Characteristics}

We identified 5495 patients with hematological malignancy and 18,906 biopsied individuals during the study period (Table 1). Among patients with hematological malignancy, there were 784 with leukemia, 3148 with lymphoma, 767 with myeloma, 322 with myelodysplastic syndrome, and 474 with myeloproliferative neoplasm. Among biopsied individuals, 2050 received bone marrow aspiration or biopsy and 16,856 received lymph node biopsy. The most frequent diagnosis was anemia for individuals with bone marrow aspiration or biopsy and infection for individuals with lymph node biopsy, followed by medical observation and evaluation for suspected diseases or conditions (Supplementary Table S3). Compared with biopsied individuals, patients with hematological malignancy were on average diagnosed at older age, more likely to be cohabitating, and had a higher prevalence of preexisting cardiovascular disease whereas a lower prevalence of preexisting psychiatric disorders (Table 1).

\section{Cardiovascular Diseases}

Among patients with hematological malignancy, we identified 305 and 925 cardiovascular diagnoses during the diagnostic workup (IR, 53.4 per 1000 person-months) and post-diagnostic period (IR, 32.5 per 1000 person-months). We also identified 646,672 cardiovascular diagnoses during the follow-up of the reference (IR, 4.7 per 1000 personmonths). Compared to reference, there was a higher rate of cardiovascular diseases during diagnostic workup (IRR 3.3, 95\% CI 2.9 to 3.8); this rate increase was greater than the rate increase during post-diagnostic period (IRR 1.9, 95\% CI 1.8 to 2.1) (Table 2). A similar pattern was observed for all subgroups of hematological malignancies, with the strongest rate increase noted for leukemia. A higher rate during the diagnostic workup was found for all individual cardiovascular diseases studied, with the strongest rate elevation noted for embolism and thrombosis (IRR 8.1, 95\% CI 5.2 to 12.8 ) (Supplementary Table S4).

Among biopsied individuals, we identified 1157 and 2240 cardiovascular diagnoses during the diagnostic workup (IR, 48.7 per 1000 person-months) and post-diagnostic period (IR, 21.2 per 1000 person-months). We found a greater IRR of cardiovascular diseases during diagnostic workup (IRR 4.9, 95\% CI 4.6 to 5.3), compared to the post-diagnostic period (IRR 1.9, 95\% CI 1.8 to 2.0), among biopsied individuals (Table 3). A similar result pattern was observed for patients receiving bone marrow aspiration or biopsy and lymph node biopsy, with a greater IRR for bone marrow aspiration or biopsy. A higher rate during the diagnostic workup was found for all individual cardiovascular diseases studied, with the strongest IRR noted for stroke (IRR 37.5, 95\% CI 34.1 to 41.2) (Supplementary Table S4). 
Table 2 Incidence Rates (Irs, Per 1000 Person-months) And Incidence Rate Ratios (IRRs) Of Cardiovascular Diseases And Psychiatric Disorders During The Diagnostic Workup And Post-Diagnostic Period Of Patients With Hematological Malignancy, A PopulationBased Cohort During 2005-2014 In Skåne, Sweden

\begin{tabular}{|c|c|c|c|c|c|c|c|c|}
\hline & \multicolumn{4}{|c|}{ Diagnostic Workup } & \multicolumn{4}{|c|}{ Post-Diagnostic Period } \\
\hline & $\begin{array}{l}\text { No. Of } \\
\text { Diagnoses }\end{array}$ & $\begin{array}{l}\text { Crude } \\
\text { IR }\end{array}$ & $\begin{array}{l}\text { IRR } \\
(95 \% \mathrm{CI})^{\mathrm{c}}\end{array}$ & $\begin{array}{l}\text { No. Of } \\
\text { Affected } \\
\text { Patients } \\
\text { (\%) }\end{array}$ & $\begin{array}{l}\text { No. Of } \\
\text { Diagnoses }\end{array}$ & $\begin{array}{l}\text { Crude } \\
\text { IR }\end{array}$ & $\begin{array}{l}\text { IRR }(95 \% \\
\text { CI) }\end{array}$ & $\begin{array}{l}\text { No. Of } \\
\text { Affected } \\
\text { Patients } \\
\text { (\%) }\end{array}$ \\
\hline \multicolumn{9}{|l|}{ Cardiovascular diseases } \\
\hline Reference $^{\mathrm{b}}$ & 646,672 & 4.7 & 1.0 & & 646,672 & 4.7 & 1.0 & \\
\hline $\begin{array}{l}\text { Patients with any hematological } \\
\text { malignancy }\end{array}$ & 305 & 53.4 & $3.3(2.9-3.8)$ & $264(4.8)$ & 925 & 32.5 & $1.9(1.8-2.1)$ & $642(12.0)$ \\
\hline Leukemia & 32 & 90.3 & $6.4(4.4-9.1)$ & $30(3.8)$ & 122 & 33.9 & $2.6(2.1-3.3)$ & $83(11.3)$ \\
\hline Myelodysplastic syndrome & 10 & 68.3 & $3.3(1.7-6.4)$ & $9(2.8)$ & 62 & 36.8 & $1.7(1.2-2.3)$ & $44(13.9)$ \\
\hline Myeloproliferative neoplasm & 23 & 107.7 & $5.4(3.6-8.1)$ & $22(4.6)$ & 110 & 41.9 & $2.0(1.5-2.6)$ & $68(14.5)$ \\
\hline Myeloma & 40 & 56.9 & $3.3(2.3-4.7)$ & $212(27.6)$ & 122 & 30.0 & $1.7(1.4-2.1)$ & $97(12.9)$ \\
\hline Lymphoma & 200 & 46.6 & $3.0(2.6-3.5)$ & $172(5.5)$ & 509 & 30.8 & $1.9(1.7-2.1)$ & $350(11.4)$ \\
\hline \multicolumn{9}{|l|}{ Psychiatric disorders } \\
\hline Reference $^{\mathrm{b}}$ & 984,268 & 7.2 & 1.0 & & 984,268 & 7.2 & 1.0 & \\
\hline $\begin{array}{l}\text { Patients with any hematological } \\
\text { malignancy }\end{array}$ & 59 & 10.4 & $2.1(1.5-2.8)$ & $48(0.9)$ & 215 & 7.6 & $1.4(1.1-1.7)$ & $114(2.1)$ \\
\hline Leukemia & 1 & 2.8 & $0.5(0.1-3.6)$ & $\mathrm{I}(0.1)$ & 29 & 8.1 & I.4 (0.9-2.3) & $19(2.6)$ \\
\hline Myelodysplastic syndrome & 1 & 6.8 & I.7 (0.3-II.2) & I $(0.3)$ & 4 & 2.4 & $0.6(0.2-1.8)$ & $3(0.9)$ \\
\hline Myeloproliferative neoplasm & I & 4.6 & $0.9(0.1-6.4)$ & $\mathrm{I}(0.2)$ & 27 & 10.3 & $2.0(I . I-3.4)$ & $12(2.6)$ \\
\hline Myeloma & 7 & 10.0 & $2.0(0.8-5.0)$ & $5(0.7)$ & 24 & 5.9 & I.I (0.6-I.9) & $15(2.0)$ \\
\hline Lymphoma & 49 & 11.4 & $2.3(1.6-3.3)$ & $40(12.7)$ & $|3|$ & 7.9 & $1.4(1.0-1.9)$ & $65(2.1)$ \\
\hline
\end{tabular}

Notes: ${ }^{a}$ Diagnostic workup was defined as the time interval starting from I week before date of diagnosis until I week after diagnosis for patients with leukemia, myelodysplastic syndrome, and myeloproliferative neoplasm, from 3 weeks until I week after diagnosis for patients with myeloma, and from 5 weeks before until I week after diagnosis for patients with lymphoma. Post-diagnostic period was defined as a 6-month period after the defined diagnostic workup for respective patients. ${ }^{\mathrm{R}}$ Reference included person-time accumulated during the follow-up of individuals that were not identified as patients with hematological malignancy or biopsied individuals as well as person-time accumulated before the defined diagnostic workup from patients with hematological malignancy and biopsied individuals. ${ }^{\mathrm{C}} \mathrm{Adjusted}$ for attained age and calendar year, sex, civil status, preexisting cardiovascular disease or psychiatric disorder, and registered parish.

Abbreviation: $\mathrm{Cl}$, confidence interval.

In the self-comparison analysis, the rate of cardiovascular diseases was statistically significantly higher during diagnostic workup, compared to the period before diagnostic workup, among patients with hematological malignancy and biopsied individuals (Table 4).

Focusing on diagnostic workup alone, we found that IRR of cardiovascular diseases was greater among younger patients and patients without preexisting cardiovascular diseases (Supplementary Table S5). Additional adjustment for frequency of healthcare visits did not change the results (Supplementary Table S6). Biopsied individuals had a slightly higher rate of cardiovascular diseases during diagnostic workup, compared to patients with hematological malignancy (Supplementary Table S7). Finally, we found that although there was a higher rate of cardiovascular diseases both before and after diagnosis or biopsy, the IRR was greater before the date of diagnosis or biopsy compared to thereafter, i.e., before the start of treatment (Figure 1).

\section{Psychiatric Disorders}

Among patients with hematological malignancy, we identified 59 and 215 psychiatric diagnoses during the diagnostic workup (IR, 10.4 per 1000 person-months) and post-diagnostic period (IR, 7.6 per 1000 person-months). We also identified 984,268 psychiatric diagnoses during the followup of the reference (IR, 7.2 per 1000 person-months). We found a greater IRR of psychiatric diseases during diagnostic workup (IRR 2.1, 95\% CI 1.5 to 2.8), compared to the post-diagnostic period (IRR 1.4, 95\% CI 1.1 to 1.7 ) (Table 2). Among different patient groups, statistically significantly higher rate as only noted for lymphoma. A rate elevation was noted for most of the studied individual psychiatric disorders (Supplementary Table S4). 
Table 3 Incidence Rates (Irs, Per 1000 Person-months) And Incidence Rate Ratios (IRRs) Of Cardiovascular Diseases And Psychiatric Disorders During The Diagnostic Workup And Post-Diagnostic Period Of Biopsied Individuals, A Population-Based Cohort Study During 2005-2014 In Skåne, Sweden ${ }^{\mathrm{a}}$

\begin{tabular}{|c|c|c|c|c|c|c|c|c|}
\hline & \multicolumn{4}{|c|}{ Diagnostic Workup } & \multicolumn{4}{|c|}{ Post-Diagnostic Period } \\
\hline & $\begin{array}{l}\text { No. Of } \\
\text { diagnoses }\end{array}$ & $\begin{array}{l}\text { Crude } \\
\text { IR }\end{array}$ & $\begin{array}{l}\text { IRR } \\
(95 \% \mathrm{CI})^{c}\end{array}$ & $\begin{array}{l}\text { No. Of } \\
\text { Affected } \\
\text { Individuals } \\
\text { (\%) }\end{array}$ & $\begin{array}{l}\text { No. Of } \\
\text { Diagnoses }\end{array}$ & $\begin{array}{l}\text { Crude } \\
\text { IR }\end{array}$ & $\begin{array}{l}\text { IRR } \\
(95 \% \mathrm{CI})^{\mathrm{C}}\end{array}$ & $\begin{array}{l}\text { No. Of } \\
\text { Affected } \\
\text { Individuals } \\
\text { (\%) }\end{array}$ \\
\hline \multicolumn{9}{|l|}{ Cardiovascular diseases } \\
\hline Reference $^{\mathrm{b}}$ & 646,672 & 4.7 & 1.0 & & 646,672 & 4.7 & 1.0 & \\
\hline All biopsied individuals & 1157 & 48.7 & $4.9(4.6-5.3)$ & $1016(5.4)$ & 2240 & 21.2 & $1.9(1.8-2.0)$ & $1420(7.6)$ \\
\hline $\begin{array}{l}\text { Individuals with bone } \\
\text { marrow aspiration or biopsy }\end{array}$ & 116 & 126.3 & $7.0(5.8-8.5)$ & $105(5.1)$ & 511 & 45.6 & $2.5(2.2-2.8)$ & $287(14.2)$ \\
\hline $\begin{array}{l}\text { Individuals with lymph node } \\
\text { biopsy }\end{array}$ & $104 \mid$ & 45.6 & $4.8(4.5-5.1)$ & $911(5.4)$ & 1729 & 18.3 & $1.8(1.7-1.9)$ & $1133(6.8)$ \\
\hline \multicolumn{9}{|l|}{ Psychiatric disorder } \\
\hline Reference $^{\mathrm{b}}$ & 984,268 & 7.2 & 1.0 & & 984,268 & 7.2 & 1.0 & \\
\hline All biopsied individuals & 748 & 31.8 & $3.1(2.9-3.4)$ & $615(3.3)$ & 2194 & 20.8 & $1.8(1.7-2.0)$ & $|26|(6.8)$ \\
\hline $\begin{array}{l}\text { Individuals with bone } \\
\text { marrow aspiration or biopsy }\end{array}$ & 6 & 6.5 & $1.0(0.4-2.1)$ & $6(0.3)$ & 115 & 10.3 & $1.4(1.1-1.9)$ & $58(2.9)$ \\
\hline $\begin{array}{l}\text { Individuals with lymph node } \\
\text { biopsy }\end{array}$ & 742 & 32.8 & $3.2(2.9-3.5)$ & $609(3.6)$ & 2079 & 22.0 & $1.9(1.8-2.0)$ & $1203(7.3)$ \\
\hline
\end{tabular}

Notes: ${ }^{a}$ Diagnostic workup was defined as the time interval starting from I week before the date of biopsy until I week after biopsy for patients with bone marrow aspiration or biopsy, and from 5 weeks before until I week after biopsy for patients with lymph node biopsy. Post-diagnostic period was defined as a 6-month period after the defined diagnostic workup for respective patients. ${ }^{b}$ Reference included person-time accumulated during the follow-up of individuals that were not identified as patients with hematological malignancy or biopsied individuals as well as person-time accumulated before the defined diagnostic workup from patients with hematological malignancy and biopsied individuals. 'Adjusted for attained age and calendar year, sex, civil status, preexisting cardiovascular disease or psychiatric disorder, and registered parish.

Abbreviation: $\mathrm{Cl}$, confidence interval.

Table 4 Incidence Rates (Irs, Per 1000 Person-months) And Incidence Rate Ratios (IRRs) Of Cardiovascular Diseases And Psychiatric Disorders During The Diagnostic Workup And Post-Diagnostic Period, Compared To The Reference Period Before The Diagnostic Workup Among Patients With Hematological Malignancy And Biopsied Individuals, A Self-Comparison Analysis ${ }^{\mathrm{a}}$

\begin{tabular}{|c|c|c|c|c|c|c|c|c|c|}
\hline & \multicolumn{3}{|c|}{ Reference Period } & \multicolumn{3}{|c|}{ Diagnostic Workup } & \multicolumn{3}{|c|}{ Post-Diagnostic Period } \\
\hline & $\begin{array}{l}\text { No. Of } \\
\text { Diagnoses }\end{array}$ & $\begin{array}{l}\text { Crude } \\
\text { IR }\end{array}$ & $\begin{array}{l}\text { IRR } \\
(95 \% \mathrm{CI})^{\mathbf{b}}\end{array}$ & $\begin{array}{l}\text { No. Of } \\
\text { Diagnoses }\end{array}$ & $\begin{array}{l}\text { Crude } \\
\text { IR }\end{array}$ & $\begin{array}{l}\text { IRR } \\
(95 \% \mathrm{CI})^{\mathbf{b}}\end{array}$ & $\begin{array}{l}\text { No. Of } \\
\text { Diagnoses }\end{array}$ & $\begin{array}{l}\text { Crude } \\
\text { IR }\end{array}$ & $\begin{array}{l}\text { IRR } \\
(95 \% \mathrm{CI})^{\mathbf{b}}\end{array}$ \\
\hline Cardiovascular diseases & & & & & & & & & \\
\hline $\begin{array}{l}\text { Patients with hematological } \\
\text { malignancy }\end{array}$ & 3885 & 12.6 & 1.0 & 305 & 53.4 & $3.0(2.5-3.6)$ & 925 & 32.5 & $1.6(1.4-1.8)$ \\
\hline Biopsied individuals & 10,925 & 9.6 & 1.0 & 1157 & 48.7 & $3.8(3.4-4.1)$ & 2240 & 21.2 & $1.5(1.4-1.6)$ \\
\hline Psychiatric disorder & & & & & & & & & \\
\hline $\begin{array}{l}\text { Patients with hematological } \\
\text { malignancy }\end{array}$ & 1453 & 4.7 & 1.0 & 59 & 10.4 & $2.1(1.4-3.1)$ & 215 & 7.6 & $1.5(1.2-1.9)$ \\
\hline Biopsied individuals & 12,049 & 10.7 & 1.0 & 748 & 31.8 & $2.5(2.2-2.7)$ & 2194 & 20.8 & $1.3(1.2-1.4)$ \\
\hline
\end{tabular}

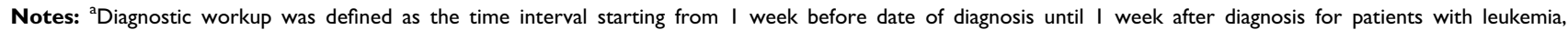
myelodysplastic syndrome, and myeloproliferative neoplasm, from 3 weeks before until I week after diagnosis for patients with myeloma, and from 5 weeks before until I week after diagnosis for patients with lymphoma. Diagnostic workup was defined as the time interval starting from I week before the date of biopsy until I week after biopsy for biopsied individuals with a bone marrow aspiration or biopsy, and from 5 weeks before until I week after biopsy for biopsied individuals with a lymph node biopsy. Postdiagnostic period was defined as a 6-month period after the defined diagnostic workup for respective patients. Reference period was defined as the time interval starting from cohort entry until the start of diagnostic workup. 'b Adjusted for attained age and calendar year, civil status, preexisting cardiovascular disease or psychiatric disorder, and registered parish.

Abbreviations: $\mathrm{Cl}$, confidence interval. 


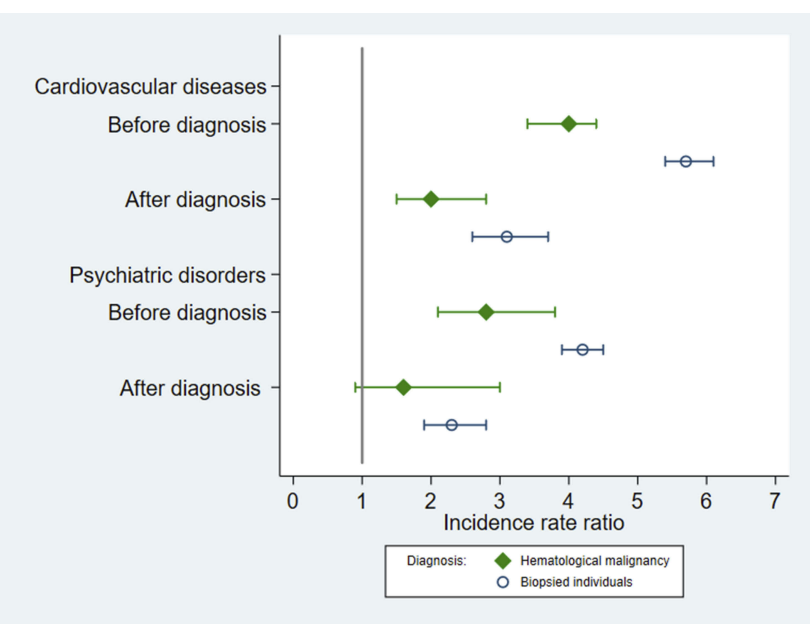

Figure I Incidence rate ratios (IRRs) and their 95\% confidence intervals (Cls) of cardiovascular diseases and psychiatric disorders during the diagnostic workup of patients with hematological malignancy or biopsied individuals, separating the analyses by before or after date of diagnosis or biopsy.

Among biopsied individuals, we identified 748 and 2194 psychiatric diagnoses during the diagnostic workup (IR, 31.8 per 1000 person-months) and post-diagnostic period (IR, 20.8 per 1000 person-months). We found a greater IRR of psychiatric disorders during diagnostic workup (IRR 3.1, 95\% CI 2.9 to 3.4), compared to post-diagnostic workup (IRR $1.8,95 \%$ CI 1.7 to 2.0 ), among biopsied individuals (Table 3 ). The rate increase did not differ clearly for depression, anxiety, and stress reaction or adjustment disorder (Supplementary Table S4).

In the self-comparison analysis, the rate of psychiatric disorders was statistically significantly higher during diagnostic workup, compared to the period before diagnostic workup, for both patients with hematological malignancy and biopsied individuals (Table 4).

Focusing on diagnostic workup alone, we found that the rate increase was greater among males and patients without preexisting psychiatric disorders (Supplementary Table S5). Further adjustment for frequency of healthcare visits did not change the results (Supplementary Table S6). Biopsied individuals had a higher rate of psychiatric disorders during diagnostic workup, compared to patients with hematological malignancy (Supplementary Table S7). We also found that although there was a higher rate of psychiatric diseases both before and after cancer diagnosis or biopsy, the rate increase was greater before diagnosis or biopsy, compared to the time between diagnosis or biopsy and treatment (Figure 1).

\section{Discussion}

To the best of our knowledge, this study is the first to demonstrate higher risks of cardiovascular diseases and psychiatric disorders during a diagnostic workup of suspected hematological malignancy, focusing not only on patients that were eventually diagnosed with hematological malignancy but also individuals that underwent a similar evaluation but without receiving a diagnosis of cancer. Previous research mainly studied patients with hematological malignancy and focused on cardiovascular diseases and psychiatric disorders after cancer treatment or during the survivorship. ${ }^{1,9,10,12,13}$ Little attention has been given to cardiovascular or psychiatric events during the clinical evaluation for a suspected malignancy or the immediate time before and after diagnosis. Our study therefore provides novel evidence for considerably increased rates of cardiovascular diseases and psychiatric disorders during this critical time window. It is interesting to note that the rate increases were much greater during the diagnostic workup, compared to the rate increases during the 6 months after the start of cancer treatment. Focusing on the diagnostic workup, the rate increases were also greater during the time before diagnosis or biopsy (while waiting for a diagnosis) compared to thereafter (while waiting for treatment).

There was a clear risk elevation for cardiovascular diseases during the diagnostic workup of patients with different hematological malignancies, although with a varying magnitude. The smallest rate increase was observed for lymphoma and the greatest rate increase for acute leukemia. This pattern is also reflected among biopsied individuals, namely that individuals receiving bone marrow aspiration or biopsy had a greater risk increase of cardiovascular diseases during the diagnostic workup, compared to individuals receiving lymph node biopsy. These results might be explained by the strong relationship between the underlying disease and the risk of cardiovascular events. For example, as hyperleukocytosis and hemorrhage are more commonly seen in leukemia, ${ }^{22,23}$ patients with leukemia tended to have a higher risk of cardiovascular diseases, especially embolism, thrombosis, and stroke, during their diagnostic workup. Similarly, as cardiac cachexia and ventricular remodeling are common in anemia, ${ }^{24}$ biopsied individuals with a diagnosis of anemia tended to have a higher risk of cardiovascular diseases, particularly heart failure and myocardial infarction, during the diagnostic workup (data not shown). 
In addition to the underlying disease, the psychological distress of going through invasive diagnostic procedures, expecting a potential diagnosis of lethal disease, and waiting for the start of cancer treatment (if confirmed with a cancer diagnosis) might also contribute to the markedly elevated rate of cardiovascular diseases during the diagnostic workup of a suspected hematological malignancy. Evidence has indeed accumulated to suggest severe psychological distress during the clinical evaluation of potential cancer. ${ }^{25-27}$ The present study corroborates and expands these previous findings by demonstrating an increased risk of psychiatric disorders during the diagnostic workup of a suspected hematological malignancy, not only among patients that were later diagnosed with cancer but also among individuals that were not destined to such disease.

During diagnostic workup, biopsied individuals had a greater rate increase of cardiovascular diseases and psychiatric disorders, especially stroke, compared to patients with hematological malignancy. The different underlying diseases between these two groups might have contributed to such difference. The most frequent diagnoses of biopsied individuals included anemia and infection, and patients with these diseases are known to have a high risk of psychiatric disorders and cardiovascular diseases ${ }^{28-34}$ particularly stroke. ${ }^{35-37}$ In contrast, a large proportion of hematological malignancy is indolent. For example, indolent non-Hodgkin lymphoma was estimated to account for around $40 \%$ of non-Hodgkin lymphoma in northern Europe. ${ }^{38,39}$ Because most indolent patients are asymptomatic, ${ }^{38}$ they are less likely to have cardiovascular comorbidities or experience symptom-related stress.

There was a decreased rate increment of cardiovascular diseases and psychiatric disorders during the week after diagnosis or biopsy (i.e., before the presumed start of primary cancer treatment for diagnosed patients), compared to the rate before diagnosis or biopsy. This finding alleviates the concern that the increased risk of cardiovascular diseases during the diagnostic workup is due purely to detection bias, assuming that patients will only be treated with anthracyclines and other targeted drugs (which might affect cardiac function) or referred to cardiologists while preparing for the start of cancer treatment (which might lead to new diagnoses of cardiovascular diseases) after receiving a diagnosis of malignancy. The smaller rate increment of these outcomes during the postdiagnostic period (i.e., 6 months after the start of primary treatment), compared to the diagnostic workup, might on the other hand reflect the effectiveness of treatment for the underlying disease on reducing the risk of cardiovascular and psychiatric comorbidities. As a result, it highlights the importance of surveillance and the usefulness of intervention for cardiovascular diseases and psychiatric disorders. Despite treatment advancements for patients with hematological malignancy during the last decades, cardiovascular and psychiatric comorbidities are still largely influencing the decision-making of clinicians with regard to the eligibility of patients for curative treatment. ${ }^{40}$ Surveillance and intervention of such comorbidities at an early stage, preferably already during the clinical evaluation of potential malignancy, could therefore make more patients eligible for curative treatment and improve prognosis.

One major strength of our study is the population-based cohort design with large sample size and complete followup. Together with the prospectively and independently collected information on the exposure and outcomes, these strengths alleviated concerns of selection and information biases. One limitation of the study is the difficulty in determining the nature of the associations noted, primarily in terms of cardiovascular diseases as we know that cardiovascular events might be the symptoms of onset for hematological malignancy and lead to a diagnostic workup. A second limitation is surveillance bias, assuming that patients with hematological malignancy and biopsied individuals had greater access to healthcare providers and therefore higher risk of being recorded with diagnoses of cardiovascular diseases or psychiatric disorders. The similar results obtained when further adjusting for frequency of healthcare visits allays this concern. The greater rate increase noted before diagnosis or biopsy compared to thereafter during the diagnostic workup, also argues against surveillance bias as a pure explanation for the observed rate increase assuming that patients with a diagnosed hematological malignancy has equally if not greater access to healthcare compared to patients that were suspected for a malignancy. Residual confounding remains a potential concern for all observational studies. The similar results obtained in the self-comparison analysis, where the rates of cardiovascular diseases and psychiatric disorders during the diagnostic workup were compared to that of the previous time period of the same individual also speaks against bias as the sole explanation for our findings.

In conclusion, in a large population-based sample, we observed markedly elevated rates of cardiovascular diseases and psychiatric disorders during the diagnostic workup of a suspected hematological malignancy. The rate increases 
were noted among patients that were eventually diagnosed with hematological malignancy as well as individuals that were similarly evaluated but did not receive a cancer diagnosis.

\section{Acknowledgments}

The authors would like to thank the Swedish Cancer Society (no. CAN 2017/322 to F.F.), the Swedish Research Council for Health, Working Life and Welfare (no. 2017-00531 to F.F.), the China Scholarship Council (No. 201407930016 to Q.S., no. 201700260291 to Q.L.) and the Karolinska Institutet (Senior Researcher Award to F.F.).

\section{Disclosure}

Therese ML Andersson took part in a private-public collaboration between Karolinska Institutet and Janssen Pharmaceuticals. Fang Fang reports grants from Swedish Cancer Society, Swedish Research Council for Health, Working Life and Welfare, Karolinska Institutet, China Scholarship Council, during the conduct of the study. The authors report no other conflicts of interest in this work.

\section{References}

1. Yu AF, Jones LW. Modulation of cardiovascular toxicity in Hodgkin lymphoma: potential role and mechanisms of aerobic training. Future Cardio. 2015;11(4):441-452. doi:10.2217/fca.15.29

2. van Leeuwen FE, Ng AK. Long-term risk of second malignancy and cardiovascular disease after Hodgkin lymphoma treatment. Hematology Am Soc Hematol Edu Program. 2016;2016(1):323-330. doi:10.1182/asheducation-2016.1.323

3. Mitchell AJ, Chan M, Bhatti H, et al. Prevalence of depression, anxiety, and adjustment disorder in oncological, haematological, and palliative-care settings: a meta-analysis of 94 interview-based studies. Lancet Oncol. 2011;12(2):160-174. doi:10.1016/S1470-2045(11)70 002-X

4. Mehnert A, Brahler E, Faller H, et al. Four-week prevalence of mental disorders in patients with cancer across major tumor entities. $J$ Clin Oncol. 2014;32(31):3540-3546. doi:10.1200/JCO.2014.56.0086

5. Loberiza FR Jr., Rizzo JD, Bredeson CN, et al. Association of depressive syndrome and early deaths among patients after stem-cell transplantation for malignant diseases. J Clin Oncol. 2002;20(8):21182126. doi:10.1200/JCO.2002.08.757

6. Wasterlid T, Mohammadi M, Smedby KE, et al. Impact of comorbidity on disease characteristics, treatment intent and outcome in diffuse large B-cell lymphoma: a Swedish lymphoma register study. J Int Med. 2019;285(4):455-468. doi:10.1111/joim.12849

7. Mohammadi M, Cao Y, Glimelius I, Bottai M, Eloranta S, Smedby KE. The impact of comorbid disease history on all-cause and cancerspecific mortality in myeloid leukemia and myeloma - a Swedish population-based study. BMC Cancer. 2015;15:850. doi:10.1186/ s12885-015-1857-x

8. Lopez-Fernandez T, Martin Garcia A, Santaballa Beltran A, et al. Cardio-Onco-hematology in clinical practice. Position paper and recommendations. Rev Esp Cardiol (English ed). 2017;70(6):474486. doi:10.1016/j.rec.2016.12.041.
9. Jurczak W, Szmit S, Sobocinski M, et al. Premature cardiovascular mortality in lymphoma patients treated with (R)-CHOP regimen - a national multicenter study. Int $J$ Cardiol. 2013;168(6):5212-5217. doi:10.1016/j.ijcard.2013.08.033

10. Farhangi H, Badiei Z, Moharreri F. Prevalence of psychiatric symptoms in all patients during maintenance therapy. Iran J Ped Hematol Oncol. 2015;5(2):77-82.

11. Bagur J, Massoubre C, Casagranda L, Faure-Conter C, TrombertPaviot B, Berger C. Psychiatric disorders in 130 survivors of childhood cancer: preliminary results of a semi-standardized interview. Pedia Blood Cancer. 2015;62(5):847-853. doi:10.1002/pbc.25425

12. van Nimwegen FA, Schaapveld M, Janus CP, et al. Cardiovascular disease after Hodgkin lymphoma treatment: 40-year disease risk. JAMA Int Med. 2015;175(6):1007-1017. doi:10.1001/jamainternmed.2015.1180

13. van Nimwegen FA, Schaapveld M, Cutter DJ, et al. Radiation doseresponse relationship for risk of coronary heart disease in survivors of Hodgkin lymphoma. J Clin Oncol. 2016;34(3):235-243. doi:10.1200/ JCO.2015.63.4444

14. Peat G, Bergknut C, Frobell R, Joud A, Englund M. Population-wide incidence estimates for soft tissue knee injuries presenting to healthcare in southern Sweden: data from the Skane Healthcare Register. Arthritis Res Ther. 2014;16(4):R162. doi:10.1186/ar4678

15. Cancercentrum. Waiting time of lymphoma and chronic lymphoid leukemia according to Swedish standardized care process. Available from: https://www.cancercentrum.se/samverkan/cancerdiagnoser/ blod-lymfom-myelom/lymfom-lymfkortelcancer/vardforlopp-lym fom/redovisning-vantetid/. Accessed September 30, 2018.

16. Cancercentrum. Waiting time of myeloma according to Swedish standardized care process. Available from: https://www.cancercentrum.se/ samverkan/cancerdiagnoser/blod-lymfommyelom/myelom/vardfor lopp-myleom/redovisning-vantetid/. Accessed September 30, 2018.

17. Cancercentrum. Waiting time of acute leukemia according to Swedish standardized care process. Available from: https://www.cancercentrum. se/samverkan/cancerdiagnoser/blod-lymfom-myelom/akut-myeloiskleukemi-aml-inkl-akut-oklassificerad-leukemi-aul/vardforlopp/redovisn ing-vantetid/. Accessed September 30, 2018.

18. Cancercentrum. Report of Swedish national quality register for acute myeloid leukemia, 1997-2014. Available from: https://www.cancer centrum.se/globalassets/cancerdiagnoser/blod-lymfom-myelom/aml/ aml-arsrapport-2016_20170206.pdf. Accessed September 30, 2018.

19. Cancercentrum. Report of Swedish national quality register for lymphoma, 2000-2017. Available from: https://www.cancercentrum.se/glo balassets/cancerdiagnoser/blod-lymfom-myelom/lymfom/rapporter/ lymfomarsrapport2000-2017_1.pdf. Accessed September 30, 2018.

20. Cancercentrum. Applicable Care Program of acute myeloid leukemia. Available from: https://www.cancercentrum.se/samverkan/cancerdiag noser/blod-lymfom-myelom/akut-myeloisk-leukemi-aml-inkl-akutoklassificerad-leukemi-aul/vardprogram/gallande-vardprogram/. Accessed October 13, 2019.

21. Cancercentrum. Applicable Care Program of lymphoma. Available from: https://www.cancercentrum.se/samverkan/cancerdiagnoser/ blod-lymfom-myelom/lymfom-lymfkortelcancer/vardprogram/. Accessed October 13, 2019.

22. Castelli R, Ferrari B, Cortelezzi A, Guariglia A. Thromboembolic complications in malignant haematological disorders. Curr Vasc Pharmacol. 2010;8(4):482-494. doi:10.2174/157016110791330799

23. Chen $\mathrm{CY}$, Tai $\mathrm{CH}$, Cheng $\mathrm{A}$, et al. Intracranial hemorrhage in adult patients with hematological malignancies. BMC Med. 2012;10:97. doi:10.1186/1741-7015-10-97

24. Mozos I. Mechanisms linking red blood cell disorders and cardiovascular diseases. Biomed Res Int. 2015;2015:682054. doi:10.1155/2015/682054

25. McCaffery KJ, Irwig L, Turner R, et al. Psychosocial outcomes of three triage methods for the management of borderline abnormal cervical smears: an open randomised trial. BMJ. 2010;340:b4491. doi:10.1136/bmj.b4491 
26. Awsare NS, Green JS, Aldwinckle B, Hanbury DC, Boustead GB, McNicholas TA. The measurement of psychological distress in men being investigated for the presence of prostate cancer. Prostate Cancer Prostatic Dis. 2008;11(4):384-389. doi:10.1038/pcan.20 08.21

27. Lu D, Andersson TM, Fall K, et al. Clinical diagnosis of mental disorders immediately before and after cancer diagnosis: a nationwide matched cohort study in Sweden. JAMA Oncol. 2016;2 (9):1188-1196. doi:10.1001/jamaoncol.2016.0483

28. Baena-Diez JM, Garcia-Gil M, Comas-Cufi M, et al. Association between chronic immune-mediated inflammatory diseases and cardiovascular risk. Heart. 2018;104(2):119-126. doi:10.1136/heartjnl2017-311279

29. Kim JH, Shah P, Tantry US, Gurbel PA. Coagulation abnormalities in heart failure: pathophysiology and therapeutic implications. Curr Heart Fail Rep. 2016;13(6):319-328. doi:10.1007/s11897-016-03 08-6

30. de Lau LM, Leebeek FW, de Maat MP, Koudstaal PJ, Dippel DW. A review of hereditary and acquired coagulation disorders in the aetiology of ischaemic stroke. Int J Stroke. 2010;5(5):385-394. doi:10. 1111/j.1747-4949.2010.00468.x

31. Eurich DT, Marrie TJ, Minhas-Sandhu JK, Majumdar SR. Risk of heart failure after community acquired pneumonia: prospective controlled study with 10 years of follow-up. BMJ (Clinical Research ed) 2017;356:j413. doi:10.1136/bmj.j413

32. Tseng $\mathrm{CH}$, Huang WS, Muo $\mathrm{CH}$, Chang YJ, Kao $\mathrm{CH}$. Increased depression risk among patients with chronic osteomyelitis. $J$ Psychosom Res. 2014;77(6):535-540. doi:10.1016/j.jpsychores.2014. 09.008

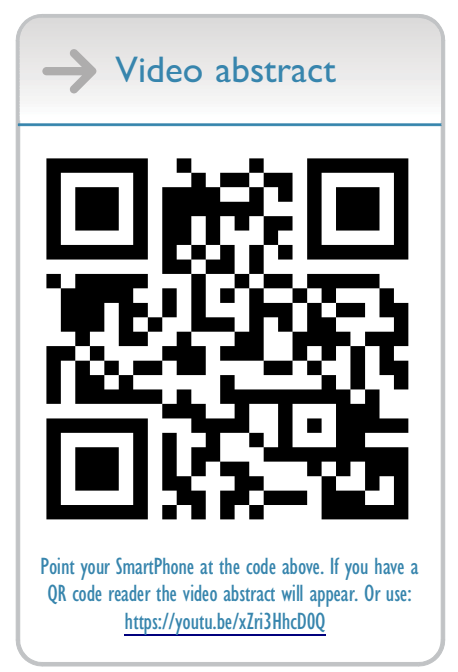

Clinical Epidemiology

\section{Publish your work in this journal}

Clinical Epidemiology is an international, peer-reviewed, open access, online journal focusing on disease and drug epidemiology, identification of risk factors and screening procedures to develop optimal preventative initiatives and programs. Specific topics include: diagnosis, prognosis, treatment, screening, prevention, risk factor modification,

Submit your manuscript here: https://www.dovepress.com/clinical-epidemiology-journal
33. Siegmann EM, Muller HHO, Luecke C, Philipsen A, Kornhuber J, Gromer TW. Association of depression and anxiety disorders with autoimmune thyroiditis: a systematic review and meta-analysis. JAMA Psychiatry. 2018;75(6):577-584. doi:10.1001/jamapsychiatry.2018.0190

34. Vulser H, Wiernik E, Hoertel N, et al. Association between depression and anemia in otherwise healthy adults. Acta Psychiatr Scand. 2016;134(2):150-160. doi:10.1111/acps.2016.134.issue-2

35. Sico JJ, Phipps MS, Concato J, et al. Thrombocytopenia and in-hospital mortality risk among ischemic stroke patients. J Stroke Cerebrovasc Dis. 2013;22(7):e99-e102. doi:10.1016/j.jstrokecerebrovasdis.2012.08.005

36. Miller EC, Elkind MS. Infection and stroke: an update on recent progress. Curr Neurol Neurosci Rep. 2016;16(1):2. doi:10.1007/ s11910-015-0602-9

37. Arkema EV, Svenungsson E, Von Euler M, Sjowall C, Simard JF. Stroke in systemic lupus erythematosus: a Swedish population-based cohort study. Ann Rheum Dis. 2017;76(9):1544-1549. doi:10.1136/ annrheumdis-2016-210973

38. Lunning MA, Vose JM. Management of indolent lymphoma: where are we now and where are we going. Blood Rev. 2012;26(6):279-288. doi:10.1016/j.blre.2012.09.004

39. Anderson JR, Armitage JO, Weisenburger DD. Epidemiology of the non-Hodgkin's lymphomas: distributions of the major subtypes differ by geographic locations. Non-Hodgkin's Lymphoma Classification Project. Ann Oncol. 1998;9(7):717-720.

40. van der Poel MW, Mulder WJ, Ossenkoppele GJ, et al. Comorbidity and treatment decision-making in elderly non-Hodgkin's lymphoma patients: a survey among haematologists. Neth J Med. 2014;72 (3):165-169. systematic reviews, risk \& safety of medical interventions, epidemiology \& biostatistical methods, and evaluation of guidelines, translational medicine, health policies \& economic evaluations. The manuscript management system is completely online and includes a very quick and fair peer-review system, which is all easy to use. 